\title{
Wenn es eng wird
}

\section{Erhard Taverna}

${ }^{*}$ www.ecopop.ch
Menschenmengen lassen sich nach physikalischen Gesetzen beschreiben. Vier Leiber pro Quadratmeter entsprechen einem urbanen Samstags- oder Weihnachtsverkauf. Ab sieben Leibern, wie zum Beispiel an der Love-Parade in Duisburg, wird die Menge zu einer Art flüssigen Masse, unkontrollierbar und panikanfällig.

Ganz so weit sind wir noch nicht, doch auffällig viel ist in allen Medien von der Acht-MillionenSchweiz die Rede. Vom Wachstum der Siedlungsflächen, vom Ausbau der Verkehrsstrukturen und abnehmender Biodiversität, welch Plastikwort für eine Katastrophe (!), von 16000 Stunden Verkehrsstau pro Jahr, vollbelegten Zügen, übernutzten Erholungsräumen und fast überall längeren Wartezeiten.

Nichts daran ist neu, denn seit mindestens vierzig Jahren erscheinen regelmässig Analysen, Statistiken, Trendmeldungen und besorgte Prognosen. Lösungen wurden immer angeboten, in den 1970ern hiess das «Small is beautiful», und in den 80ern «Wege aus der Wachstumsfalle», oder «Qualitatives Wachstum» in den 90ern. Hans Weiss, Initiant der Rettungsaktion Greina-Hochebene, monierte über die «Unteilbare Landschaft», der Psychiater Hanspeter Padrutt beklagte die Misere in seinem Buch «Der epochale Winter». Die Denkfabriken der Wirtschaft sehen das naturgemäss anders. Sie messen am steigenden Bruttoinlandprodukt den nationalen Wohlstand, denn Wachstum sichert Arbeitsplätze und Renten, so der Refrain seit Jahrzehnten. Die Parteien reduzieren das Problem auf griffige Parolen, mit denen sie Stimmen fangen. Ausdruck des trotzdem zunehmenden Unbehagens sind regelmässig Initia-

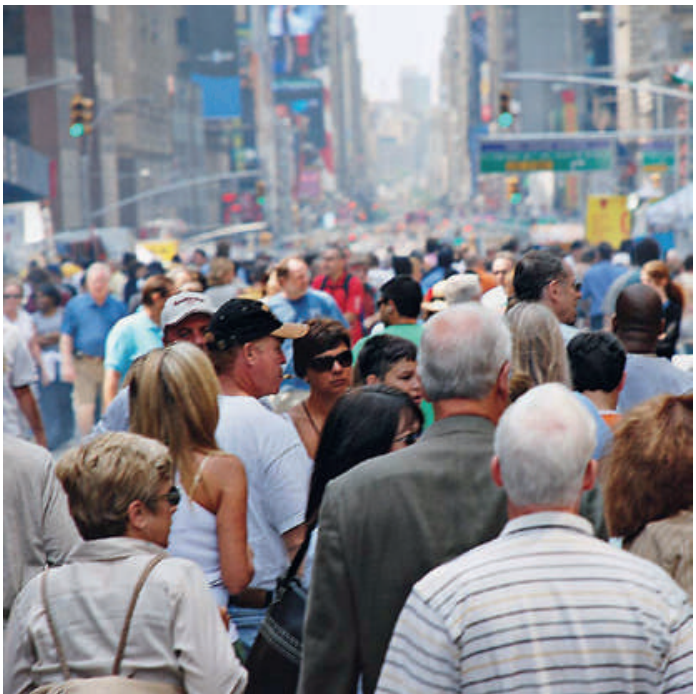

tiven, zum Schutz der Hochmoore und der Alpen, gegen Abzocker, zur Begrenzung des Zweitwohnungsbaus oder zur besseren Migrationskontrolle. Nicht wenige Politiker bringen es fertig, dieses Unbehagen zu schüren und gleichzeitig die Verursacher in Schutz zu nehmen, indem sie wirksame Gegenmassnahmen regelmässig torpedieren. Der Initiativtext der Vereinigung Ecopop, «Stopp der Überbevölkerung - zur Sicherung der natürlichen Lebensgrundlagen» geht zumindest einen Schritt in die richtige Richtung. Art. 73 a (neu), Absatz 3 der zu ändernden Bundesverfassung hält fest: «Die ständige Wohnbevölkerung darf infolge Zuwanderung im dreijährigen Durchschnitt nicht mehr als 0,2\% pro Jahr wachsen.» Für das Gesundheitswesen übrigens kein Problem, denn gemäss SECO arbeiteten 2009 nur 3,4\% der Zugewanderten, das heisst 4460 Personen in medizinischen Einrichtungen, davon 1600 in der Pflege. Sichert die alleinige Einschränkung der Zuwandererzahlen unsere Lebensgrundlagen? Mit der Forderung, mindestens 10\% der Mittel internationaler Entwicklungszusammenarbeit zur Förderung der Familienplanung in armen Ländern zu verwenden, begibt sich das Initiativkomitee aufs Glatteis. Da gäbe es vorher noch sehr viel wichtigere Hausaufgaben zu lösen, die das Argumentarium leider nicht erwähnt. Genügt es, nur noch die ganz Reichen, die Kaderleute und die ausgebildeten Spezialisten $\mathrm{zu}$ importieren? Wer besorgt die Dreckarbeit? Eine absolut korrekturbedürftige Migrationspolitik gerät zum Prügelknaben, sie wird zum Alibi, damit im Inland alle so weiterwursteln können wie bisher. Was wurde aus der Agenda 21 und der Bundesstrategie einer nachhaltigen Entwicklung? Der Begriff der Nachhaltigkeit ist längst zur Leerformel verkommen. Daran ändern auch die unzähligen Broschüren nichts, die sich mit der Erhaltung einiger Biotope begnügen oder von technischen Lösungen das Heil erwarten. Wachstum und Ökologie sind mit heutigen Mitteln unvereinbar, grenzenlose Mobilität ist umweltschonend nicht zu haben. Wachstum, als universales Mittel, ist meistens die Krankheit, die sie zu heilen vorgibt. Auch der im Zeichen der globalen Finanzkrise beschworene Konjunkturaufschwung bringt dem einzelnen Bürger kaum Vorteile, denn Mehreinnahmen verteilen sich einfach auf mehr Köpfe.

Es wird immer enger, das haben alle bisherigen Rezepte nicht verhindern wollen oder können. Gepredigt wird die Anpassung an das scheinbar Unvermeidliche: schnellere Rolltreppen, weniger Sitzplätze und Benimm-dich-Regeln, die zu mehr Tempo 
aufrufen: Beeile dich beim Aus- und Einsteigen, sei geschmeidig und flink, shoppe rund um die Uhr. Bummler und Träumer sind kleingeistig und unhöflich, provinzielle Ewiggestrige, verkalkte Romantiker. Distanz hat einen Preis, wer zu wenig Geld hat, ist selber schuld. Die Konsumwelt bietet Fluchtstrategien, man kann sich Stöpsel in die Ohren stecken oder eine Augmented-Reality-Brille aufsetzen. Auf alten Fotos meiner Heimatstadt wächst der Wald bis in die heutige Kernzone, Strassen und Plätze wirken fast leer. Der Fernblick zeigt ein Tal, in dem jede
Ortschaft durch weite Felder von der anderen getrennt ist. Im Gegensatz zu Avenir Suisse macht mir eine 10-Millionen-Schweiz Angst. Der materielle Fortschritt ist ein Nullsummenspiel geworden, in dem jedem Gewinn ein Verlust gegenübersteht. Franz Hohler hat das in seinem Lied «E Foti» genial zu einem Bild verkürzt. Der alte Bauer holt am Bankschalter sein Geld und sieht dort ein Foto von seiner verkauften Liegenschaft hängen: «Das Geld isch vom Land mit dr Schür, und wo d' Schür xi isch, stoht jetz e Bank»... 